\title{
5.8 GHz High-Efficiency RF-DC Converter Based on Common-Ground Multiple-Stack Structure
}

\author{
Jongseok Bae ${ }^{1}\left(\mathbb{D}\right.$, Sang-Hwa Yi ${ }^{2}$, Woojin Choi ${ }^{1}{ }^{(\mathbb{C}}$, Hyungmo Koo $^{1} \mathbb{(}$, Keum Cheol Hwang ${ }^{1}(\mathbb{D}$, \\ Kang-Yoon Lee ${ }^{1}$ and Youngoo Yang ${ }^{1, *(\mathbb{C}}$ \\ 1 College of Information and Communication Engineering, Sungkyunkwan University, 2066 Seobur-ro, \\ Jangan-gu, Suwon 16419, Korea \\ 2 Electrical Environment Research Center, Korea Electrotechnology Research Institute, \\ Changwon-si 51543, Korea \\ * Correspondence: yang09@skku.edu; Tel.: +82-31-290-7976
}

Received: 25 June 2019; Accepted: 23 July 2019; Published: 24 July 2019

\begin{abstract}
This paper presents a $5.8 \mathrm{GHz}$ RF-DC converter for high conversion efficiency and high output voltage based on a common-ground and multiple-stack structure. An RF isolation network (RFIN) for the multiple-stack RF-DC converter is proposed to combine the DC output voltage of each stack without separating its RF ground from the DC ground. The RFIN is designed using micro-strip transmission lines on a single-layer printed circuit board (PCB) with a common ground for the bottom plate. A 4-stack RF-DC converter based on a class-F voltage doubler for each stack was implemented to verify the proposed RFIN for the multiple-stack and common-ground structure. The performances of the implemented 4-stack RF-DC converter were evaluated in comparison to the single-stack converter that was also implemented. The size of the implemented 4-stack RF-DC converter using bare-chip Schottky diodes is $24 \mathrm{~mm} \times 123 \mathrm{~mm}$ on a single-layer PCB. For an input power of $21 \mathrm{dBm}$ for each stack of the RF-DC converter with a load resistance of $4 \mathrm{k} \Omega$, a high efficiency of $73.1 \%$ and a high DC output voltage of $34.2 \mathrm{~V}$ were obtained.
\end{abstract}

Keywords: microwave power transfer; rectenna array; rectifier; multiple-stack RF-DC converter; RF isolation network; voltage doubler

\section{Introduction}

Microwave power transmission (MPT) technology has been developed for various wireless charging applications, such as space solar power systems, internet of things (IoT) sensors, medical devices, RF energy harvesting systems, and mobile devices. The MPT system has the advantage of charging distance, compared to popular wireless charging systems that are based on electro-magnetic resonance or magnetic coupling methods [1-8]. However, the efficiency of the MPT system, which is mainly determined by the efficiency of the transmitter (Tx), path loss between the Tx and receiver (Rx), and the RF-DC conversion efficiency of the Rx, is very poor.

Figure 1 shows a block diagram of an MPT system based on massive Tx and Rx antenna arrays, which are required to reduce the path loss between the Tx and Rx. A phased array is required for the Tx to sharply form and precisely steer the antenna beam. The Rx usually consists of an antenna array, RF-DC converters or rectifiers, DC-DC converters, and the load [7]. One or multiple DC-DC converters are required between the load and the RF-DC converters to generate a constant and stable DC output voltage. The overall efficiency of the Rx is determined by the efficiencies of the RF-DC converter and the DC-DC converter. 


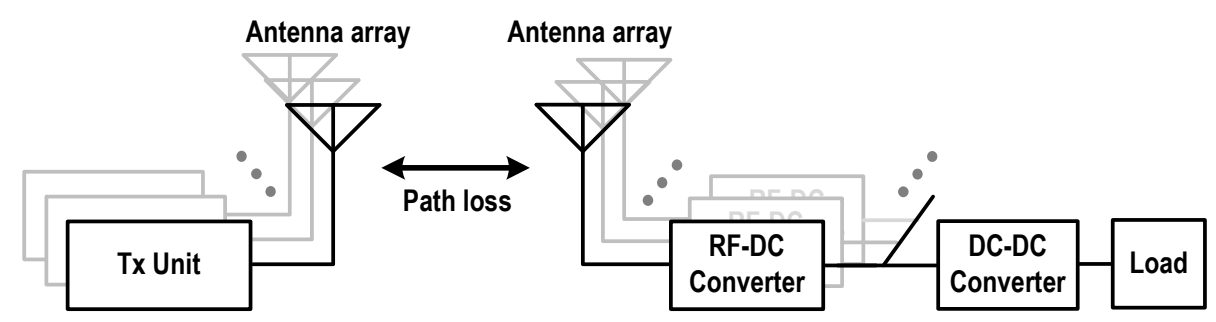

Figure 1. A block diagram of the MPT system based on massive Tx and Rx antenna arrays.

If the required output DC voltage at the load is higher than the output voltage of the RF-DC converter, a boost DC-DC converter must be used. Otherwise, if the output voltage of the RF-DC converter is sufficiently higher than the required output DC voltage at the load, a buck DC-DC converter can be used, which is generally simpler and more efficient than a boost converter. For higher efficiency and simpler circuit for the Rx, it is often desirable for the RF-DC converter to have high output DC voltage, in addition to high efficiency.

The RF-DC converter consists of an input matching circuit, Schottky diodes, and a low-pass filter. The output DC voltage of the RF-DC converter is dependent on the circuit structure and the number of diode stack. Compact structures using a shunt diode or a series diode generally have the disadvantage of low output voltage. Since voltage doubler structures have two Schottky diodes, the output voltage becomes about twice as high as that of the single diode structures [5]. The output voltage can be boosted by increasing the number of diode stack, while sacrificing the conversion efficiency mainly due to the increased input matching loss.

Since RF-DC converters have been applied to various sensors that acquire energy or information for the operation from the input RF signal in addition to the MPT systems, a lot of previous studies of various aspects can be found [9-17]. Harmonic termination can be used to improve the conversion efficiency of the RF-DC converter based on the Schottky diode [9-16]. The authors in [9] realized a class-C operation at $2.45 \mathrm{GHz}$ was realized using a shunt diode with short-circuited second and third harmonics, and reported an efficiency of $72.8 \%$ and an output voltage of $1.91 \mathrm{~V}$ using an input power of $8 \mathrm{dBm}$ with a load resistance of $742 \Omega$. A Class-F input matching network with a short-circuited second harmonics and an open-circuited third harmonics was proposed [10,11]. The author in [10] reported a class-F rectifier at $2.45 \mathrm{GHz}$ with a third harmonic matching circuit, and with even harmonic cancellation characteristics by using dual diodes and reported an efficiency of $75.4 \%$ at an input power of $20 \mathrm{dBm}$ and a load resistance of $1 \Omega$. The authors in [11] reported an efficiency of $79.5 \%$ using a shunt diode at an input power of $17.65 \mathrm{dBm}$ and a frequency of $5.8 \mathrm{GHz}$. The authors in [12] reported a class-F voltage doubler at $5.8 \mathrm{GHz}$ with an efficiency of $71 \%$ and an output voltage of $5 \mathrm{~V}$ at an input power of $14.77 \mathrm{dBm}$ and a load resistance of $1300 \Omega$.

For the massive Rx array, power-combining methods for the received power from each antenna are very important to increase the DC output power, and to generate the required DC voltage [18-26]. The RF power-combining methods can increase the input power to the RF-DC converter, though the combiner has considerable size and loss. The DC power-combining methods include current-combining and voltage-combining methods [18-24]. The authors in [26] introduced a hybrid power-combining rectenna array using both RF power-combining and DC power-combining methods for higher received power. However, power-combining methods have not yet been comprehensively analyzed and compared from the systems' point of view yet.

In this paper, three power-combining methods of the Rx array for the MPT systems were briefly compared and analyzed. To increase the output DC voltage of the Rx for the MPT systems, an RFIN, which can be implemented using microstrip transmission lines on a single-layer PCB, is proposed for the common-ground and multiple-stack RF-DC converter. Compared to the conventional voltage-combining methods, the proposed voltage-combining circuit using the RFIN 
could be implemented on a single-layer PCB with a very simple structure. To verify the proposed RFIN, a 5.8 GHz 4-stack RF-DC converter using a class-F doubler as a unit stack was designed and implemented for high conversion efficiency and high output voltage. The measured performances of the implemented 4-stack RF-DC converter are presented in comparison to the implemented single-stack converter and some previously reported RF-DC converters.

\section{Power-Combining Method}

Figure 2 shows three representative power-combining methods for a rectenna array. For a massive $R x$ array, three methods can be selectively mixed and applied for the optimized system design. RF signals, which are received from multiple Rx antennas, can be directly combined using an RF power combiner for an RF-DC converter, as shown in Figure 2a. The input power to the RF-DC converter can be increased, but, in general, the RF power combiner has considerable loss. If the RF power received from each antenna is not enough for the RF-DC converter to have high efficiency or to work properly, the RF power-combining method must be considered.

Figure $2 b, c$ are diagrams for the DC current-combining and the DC voltage-combining methods, respectively. Both methods can be categorized as DC power combining methods, which in general have relatively small loss and simple structure. For the current-combining Rx with $\mathrm{N}$ rectennas, the total output current $\left(I_{O U T}\right)$ at the load is simply given as the sum of the output DC currents of the multiple parallel RF-DC converter stages:

$$
I_{o u t}=I_{o u t, 1}+I_{o u t, 2}+\cdots+I_{o u t, N}
$$

where $I_{\text {out }, N}$ is an output current of the N-th RF-DC converter. Then, the total power at the load $\left(P_{D C}\right)$ and the output voltage $\left(V_{\text {out }}\right)$ can be derived using $I_{\text {out }}$ as:

$$
\begin{gathered}
P_{D C}=\left(I_{\text {out }}\right)^{2} \times R_{L}, \\
V_{\text {out }}=I_{\text {out }} \times R_{L} .
\end{gathered}
$$

Figure $2 \mathrm{c}$ shows a voltage combining method using a multiple-stack RF-DC converter. The DC output of the $i$-th stack is fed to the RF ground of the $(i+1)$-th stack. Then, the output DC voltage of the $\mathrm{N}$ stack RC-DC converter $\left(V_{\text {out }}\right)$ becomes about $\mathrm{N}$ times the output $\mathrm{DC}$ voltage of each stack.

$$
V_{\text {out }}=V_{\text {out }, 1}+V_{\text {out }, 2}+\cdots+V_{\text {out }, N}
$$

where $V_{\text {out }, N}$ is the output voltage of the N-th RF-DC converter. Then, the total power at the load $\left(P_{D C}\right)$ and the output current $\left(I_{\text {out }}\right)$ can be derived using $V_{\text {out }}$ as:

$$
\begin{gathered}
P_{D C}=\frac{\left(V_{\text {out }}\right)^{2}}{R_{L}}, \\
I_{\text {out }}=\frac{V_{\text {out }}}{R_{L}} .
\end{gathered}
$$

For the massive antenna array, the RF power-combining and two DC power combining methods can be appropriately used for the overall Rx system. The Rx structure for power-combining should be optimized through careful consideration of the nominal received power, the number of antennas, the required output DC voltage for the load, and so on. 


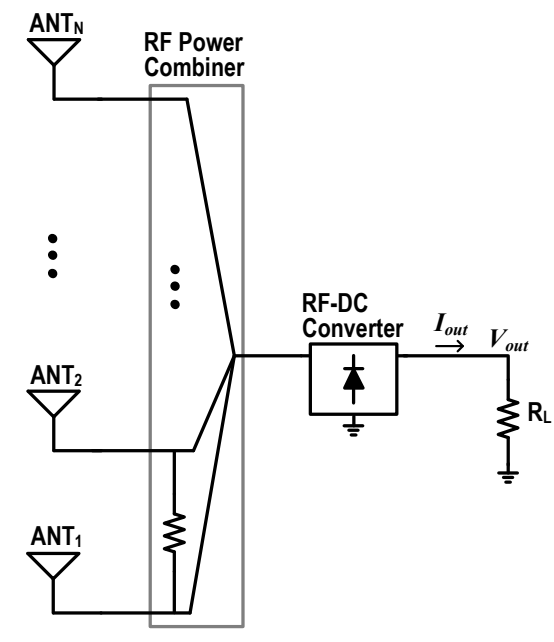

(a)

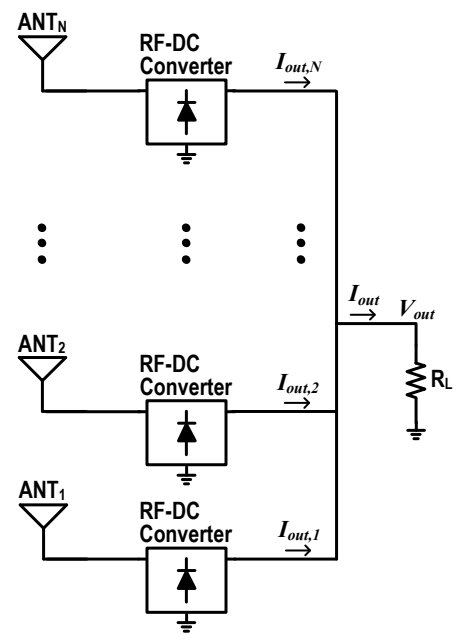

(b)

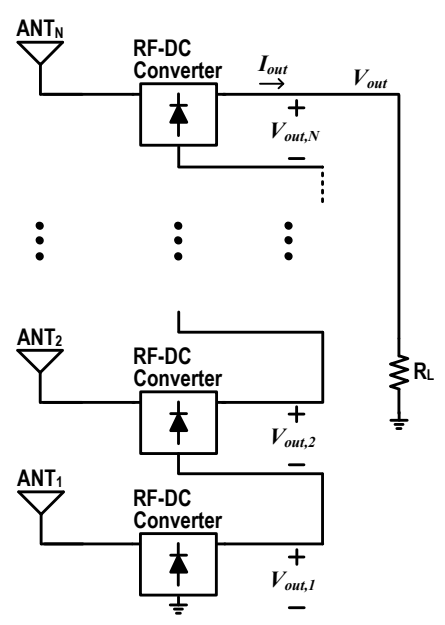

(c)

Figure 2. Power-combining methods for rectenna array, (a) RF power-combining; (b) DC current-combining; and (c) DC voltage-combining.

\section{Design of the Proposed RF-DC Converter}

\subsection{Common-Ground Multiple-Stack Structure}

For the Rx with a massive antenna array, DC power-combining in either current or voltage form is required. In particular, appropriate use of the voltage-combining method allows the Rx to have optimal output DC voltage for a DC-DC converter with high efficiency. Figure 3a shows a schematic of the $\mathrm{N}$-stack RF-DC converter with the conventional voltage-combining method. Since the DC output of the i-th stack, except the first stack, is fed to the RF ground of the $(i+1)$-th stack, the RF ground of the $(i+1)$-th stack must be separated from the DC ground. Though it is very easy and simple to combine the voltage outputs from the multiple rectennas, its implementation is not as simple as its concept. Since the bottom plate of a PCB is usually used as a ground for general RF circuits, each stack must be implemented on a separated PCB, or the whole circuit must be implemented on a multi-layer PCB.

Figure $3 \mathrm{~b}$ is a schematic of the N-stack RF-DC converter with the proposed common-ground structure. Different from the conventional method, the RF and DC grounds for the proposed method are the same for all stacks. The RFIN provides the $(i+1)$-th stack with the DC output of the $i$-th stack, and also provides very low impedance at its input and output ports to isolate the RF signal. To use the whole bottom plate as common ground, the RFIN must be implemented on the top metal plate of the PCB. Section 3.3 presents how to design the RFIN. 


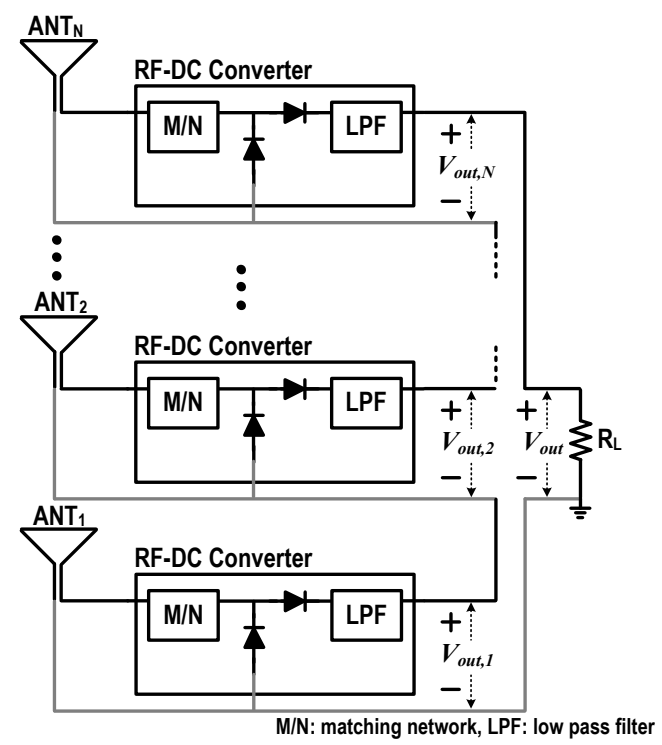

(a)

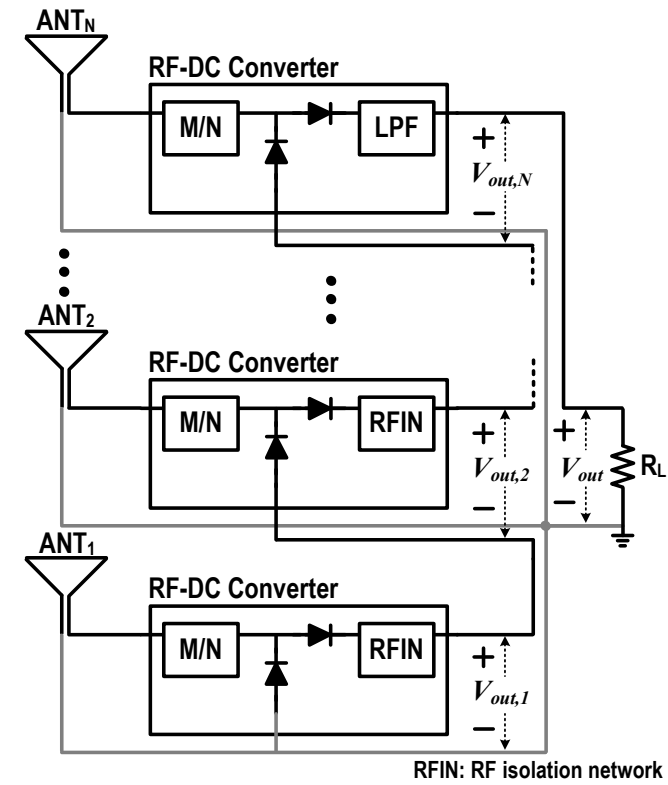

(b)

Figure 3. Schematics of the voltage combined N-stack RF-DC converters, (a) conventional and (b) proposed.

\subsection{Class-F Voltage Doubler}

To design the overall multi-stack RF-DC converter using the proposed common-ground structure, a unit RF-DC converter stack should be designed. For high conversion efficiency, a class-F voltage doubler was designed for the $5.8 \mathrm{GHz}$ band using a bare-chip Schottky diode, MACOM's MA4E1319-1, which has a very low series resistance of $4.6 \Omega$, and a junction capacitance of $0.047 \mathrm{pF}$. Since the three-terminal chip has two Schottky diodes connected in series, it is more convenient to design a voltage doubler.

Figure 4 shows a source-pull setup for the class-F voltage doubler whose source impedance must be very low for the second harmonics, and very high for the third harmonics. Since the series connection of the two diodes looks perfectly balanced at the input for the second harmonics, no second harmonic voltage can be generated at the input [11]. Figure 5a shows the efficiency contours for the input third harmonics. Due to the internal parasitic capacitance, an optimum region can be found at the slightly inductive impedance area. $C_{L}$ at the output should be very large to have only DC voltage $\left(V_{\text {out }}\right)$ at the output.

Figure $5 \mathrm{~b}$ shows the simulated efficiencies according to the input power with and without third harmonic control. Using the fundamental source impedance of $180+j 32 \Omega$, the optimum third harmonic impedance of $j 150 \Omega$ at an input power of $21 \mathrm{dBm}$, and load resistance of $1 \mathrm{k} \Omega$, the class-F voltage doubler in the source-pull condition exhibited a high efficiency of $82.0 \%$ and output DC voltage of $9.6 \mathrm{~V}$ at input power of $21 \mathrm{dBm}$, while the normal voltage doubler without third harmonic control has a $5.2 \%$ lower maximum efficiency. Figure $5 \mathrm{c}$ shows voltage and current waveforms of the Schottky diodes. 


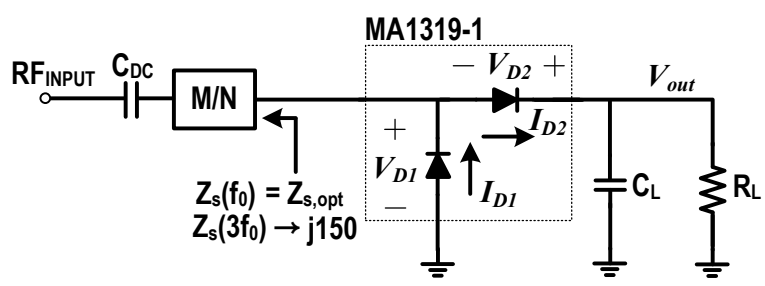

Figure 4. A source-pull setup for the class-F voltage doubler design.

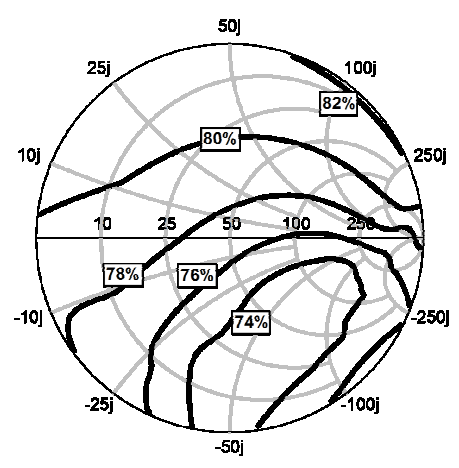

(a)

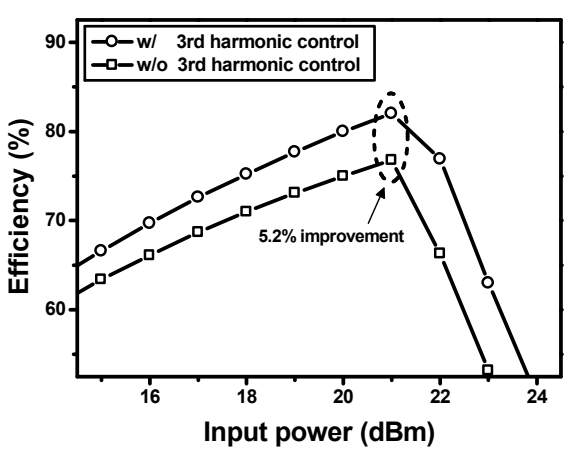

(b)
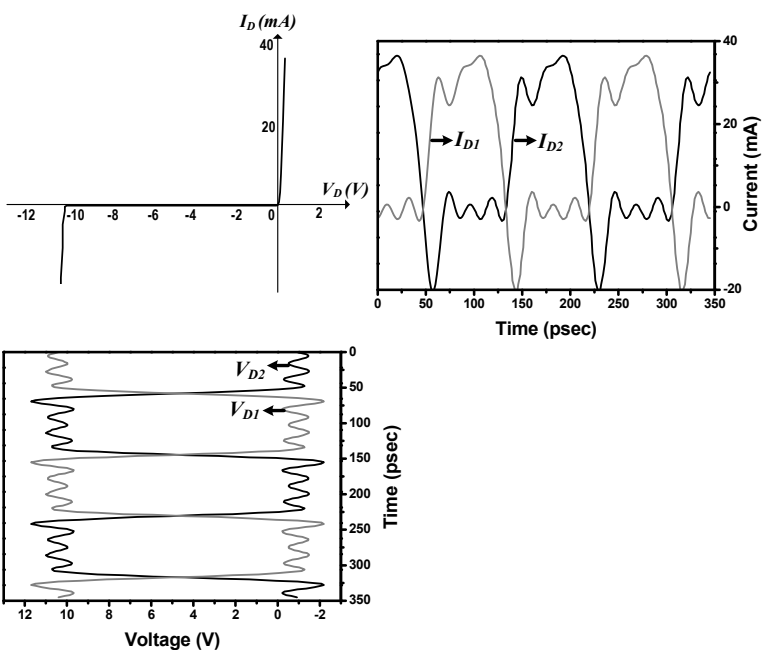

(c)

Figure 5. Simulation results of the class-F voltage doubler, (a) efficiency contours for the input third harmonics; (b) simulated efficiencies; and (c) voltage and current waveforms of the Schottky diodes.

Figure 6 shows the implemented input matching network for the fundamental and third harmonics of the proposed class-F voltage doubler. Figure 7 shows trajectories for the input impedance matching: (a) for third harmonic impedances and (b) for the fundamental impedances. The input matching network, including a bond-wire inductance of $0.3 \mathrm{nH}$, consists of series transmission lines and open stubs. In the matching network for the third harmonics, a $50 \Omega$ open stub with an electrical length of $30^{\circ}$ is used to make a short circuit at point $\mathrm{D}$ for the third harmonics. Then, a $50 \Omega$ series transmission line with an electrical length of $11^{\circ}$ and a bond-wire inductance rotate the impedance to the optimum point. The fundamental impedance matching network, before the 3rd harmonic matching network, consists of a $73^{\circ}$ series transmission line with a characteristic impedance of $50 \Omega$, a $65^{\circ}$ open stub with a characteristic impedance of $50 \Omega$, and a DC-blocking capacitor of $C_{D C}$. For accuracy, an electromagnetic field simulation tool, Keysight's Momentum, was used in the design of the input matching network. The entire input matching network showed an insertion loss of $0.2 \mathrm{~dB}$. 


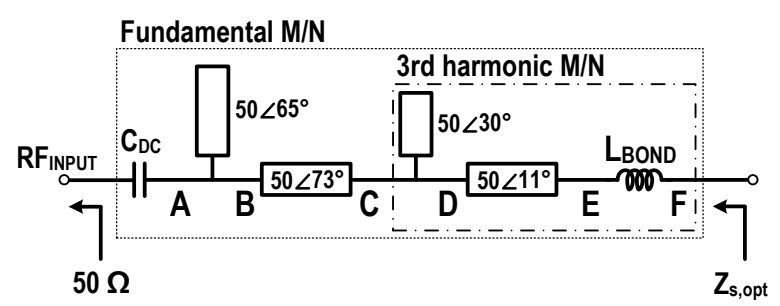

Figure 6. Schematic of the input matching network.

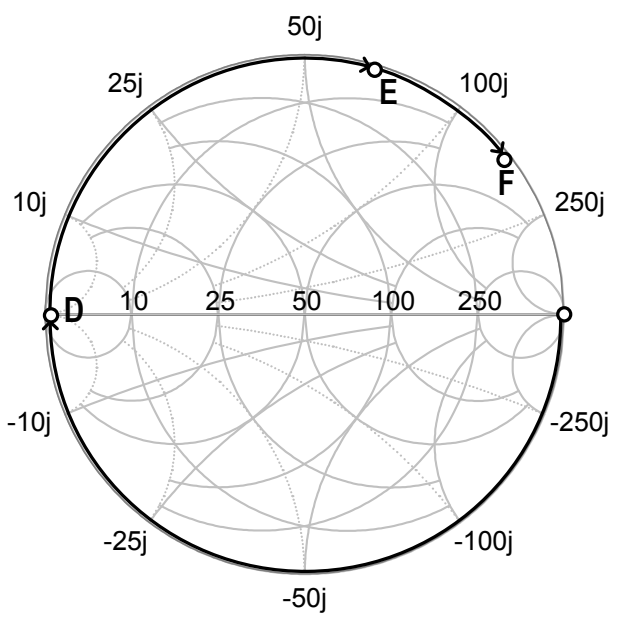

(a)

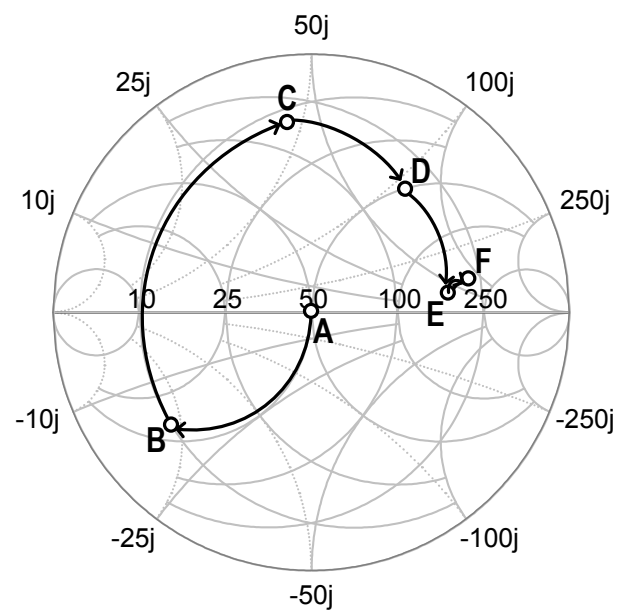

(b)

Figure 7. Trajectories for input impedance matching, (a) third harmonics and (b) fundamental.

\subsection{RFIN}

Figure 8 shows (a) a schematic of the RFIN with its ideal configuration, and (b) its practical configuration including bond wires. The RFIN is a reciprocal network and is basically designed using transmission lines. The RFIN should provide a short circuit in DC through the ports, and a ground in RF for both ports. To make an RF ground, the impedances for the fundamental and harmonics at each port were minimized. In this design, higher-order harmonics, except the second, were ignored for circuit simplicity:

$$
Z_{P 1}\left(f_{0}\right)=Z_{P 2}\left(f_{0}\right)=Z_{P 1}\left(2 f_{0}\right)=Z_{P 2}\left(2 f_{0}\right) .
$$

where $Z_{P j}\left(f_{0}\right)$ and $Z_{P j}\left(f_{0}\right)$ are the fundamental and second-harmonic impedances for the $j$-th port, respectively.

For the ideal configuration, the 2 nd harmonic impedance of $Z_{1}\left(2 f_{0}\right)$, which is the same as $Z_{P 1}\left(2 f_{0}\right)$, is obtained as $0 \Omega$ using a $45^{\circ}$ open stub. In the same way, the fundamental impedance of $Z_{3}\left(f_{0}\right)$ becomes $0 \Omega$ using a $90^{\circ}$ open stub. Then, the fundamental impedance of $Z_{2}\left(f_{0}\right)$, which is the same as $Z_{P 1}\left(f_{0}\right)$, becomes $0 \Omega$ using a $180^{\circ}$ series transmission line.

However, for the practical RFIN, bond wires, which connect the Schottky diode to the circuit board, should be considered. The bond wire can be modeled using an inductance, $L_{B O N D}$. An inductance of about $0.3 \mathrm{nH}$ was extracted for a bond wire using 3D electromagnetic (EM) simulation. The impedances for the fundamental and second harmonics of $Z_{P 1^{\prime}}$ or $Z_{P 2^{\prime}}$ are designed to reduce $Z_{P 1}$ or $Z_{P 2}$ to close to $0 \Omega$ through $L_{B O N D}$. An open stub, which was optimized to have an electrical length of $30^{\circ}$ and a characteristic impedance of $62 \Omega$, makes the second harmonic impedances of $Z_{P 1}\left(2 f_{0}\right)$ and $Z_{P 2}\left(2 f_{0}\right)$ almost $0 \Omega$, together with $L_{B O N D}$. Additionally, the fundamental impedances of $Z_{P 1}\left(f_{0}\right)$ and $Z_{P 2}\left(f_{0}\right)$ were sent to $0 \Omega$ using a $90^{\circ}$ open stub and an $170^{\circ}$ series transmission line both with a characteristic impedance of $62 \Omega$. 
Figure 9 shows the simulation results for the fundamental and second harmonic impedances of $Z_{P 1}$ (after the bond wire) and $Z_{P 1^{\prime}}$ (before the bond wire) on the Smith chart. The fundamental and second harmonic impedances after the bond wire were obtained using an EM simulation as $0.65-j 2.1 \Omega$ and $0.24+j 1.9 \Omega$, respectively. The simulated impedances are very close to $0 \Omega$, which is very important for the performances of the overall multi-stack RF-DC converter.

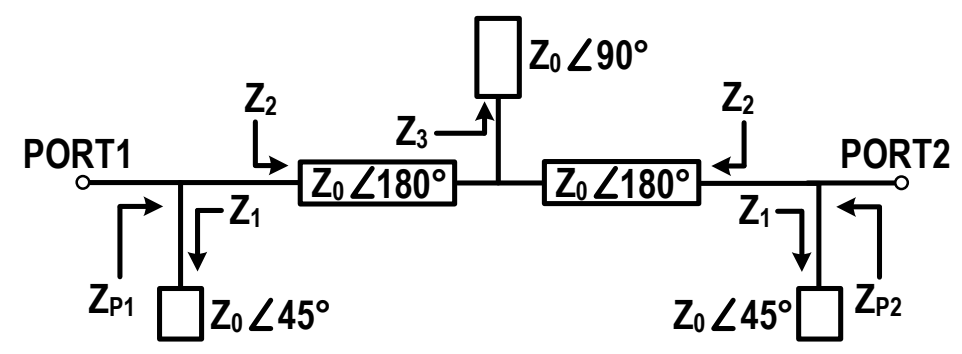

(a)

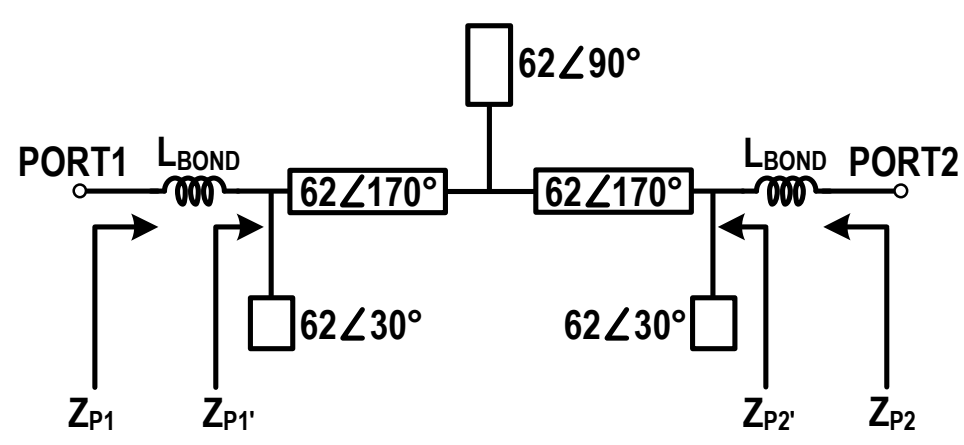

(b)

Figure 8. Schematics of the RFIN, (a) ideal configuration and (b) practical configuration including bond wires.

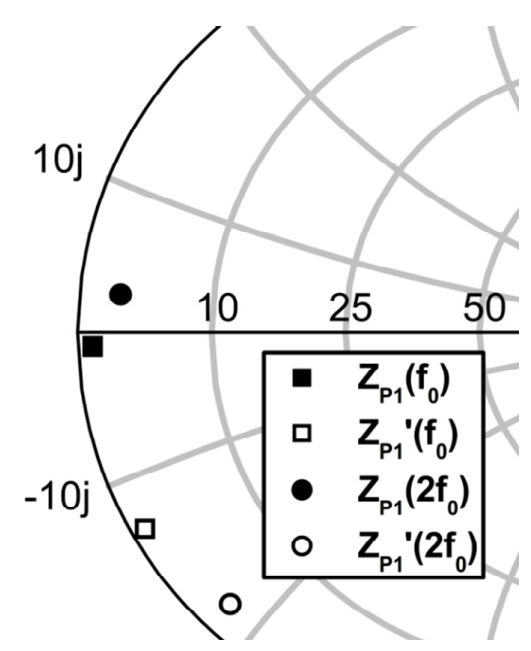

Figure 9. Fundamental and second harmonic impedances before and after the bond wire.

\subsection{Experiomental Verification}

Figure 10 shows a schematic of the implemented 4-stack RF-DC converter based on class-F voltage doublers. The 4-stack RF-DC converter was designed on a single dielectric layer PCB with a bottom 
plate as a common ground for both RF and DC. The PCB for circuit implementation is a Taconic's RF-35 with a dielectric thickness of 20 mil, a relative permittivity of 3.5, and a loss tangent of 0.0018 . The proposed RFIN isolates the RF signal, and feeds the DC voltage from one stack to the next stack. The same RF power must be supplied to each voltage doubler stack. $C_{L}$ of $3 \mathrm{pF}$ was used at the output.

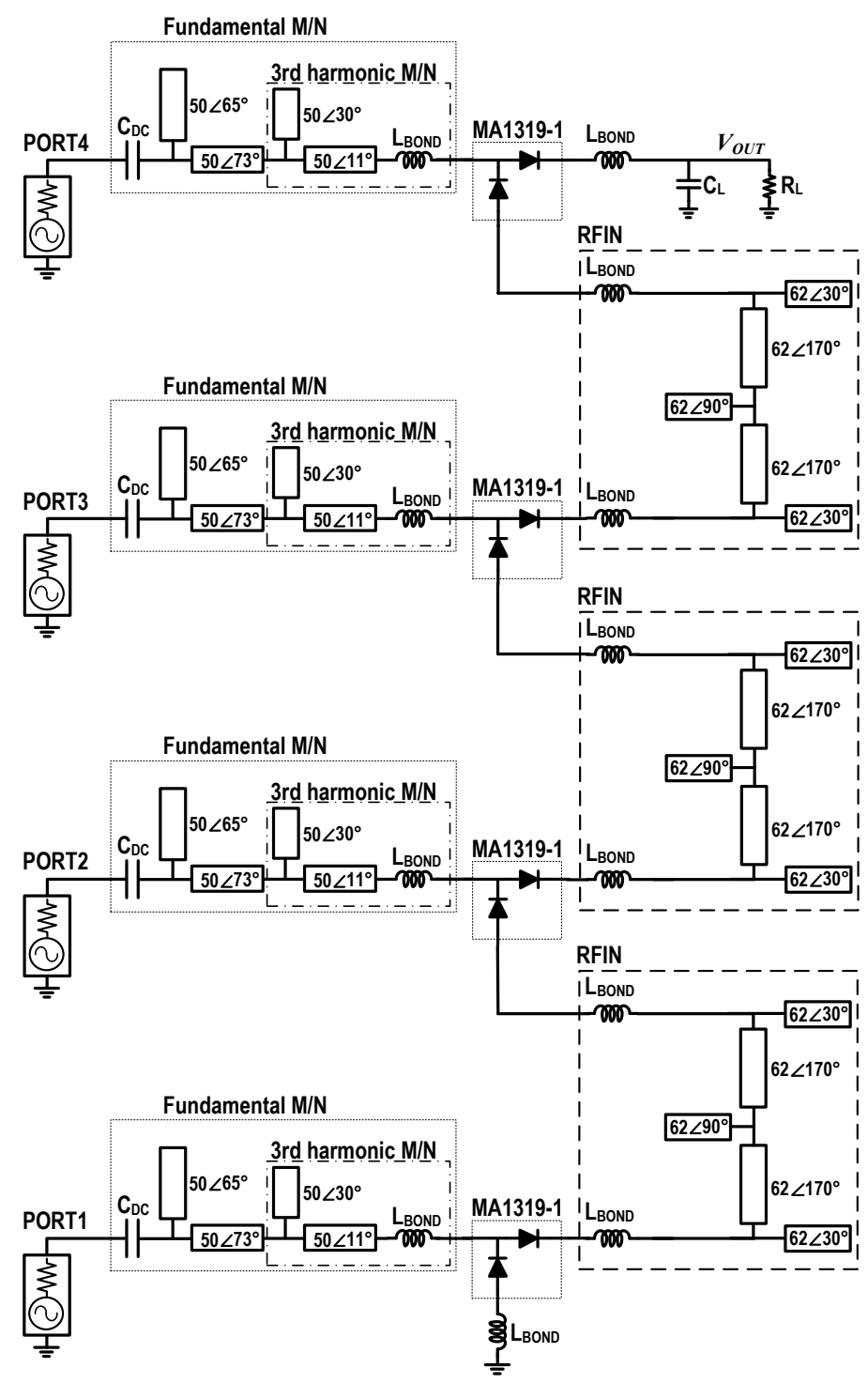

Figure 10. A schematic of the implemented 4-stack RF-DC converter based on class-F voltage doublers.

Figure 11 shows a photograph of the implemented 4-stack RF-DC converter based on class-F voltage doublers. The size of the implemented circuit is $24 \mathrm{~mm} \times 123 \mathrm{~mm}$. The Schottky diode chip, MA4E1319-1, was mounted as chip-on-board (COB). ATC's high-Q capacitors were used for both the input matching and the load. Figure 12 shows a photograph of the measurement setup. After a drive amplifier, a 4-way Wilkinson power divider equally splits the input power and supplies to the input of each voltage doubler stack. An electrical load, Maynuo's M9712, is used at the load to provide optimized load resistance. The efficiency of the 4-stack RF-DC converter was calculated using the measured DC voltage and current.

Figure 13 shows the simulated and measured efficiencies and output DC voltages for the implemented single-stack and 4-stack RF-DC converters. The input RF signal is a continuous-wave (CW) with a frequency of $5.8 \mathrm{GHz}$. The single-stack RF-DC converter demonstrated an efficiency of $73.6 \%$ and an output DC voltage of $8.58 \mathrm{~V}$ at an RL of $1 \mathrm{k} \Omega$, and an input power of $21 \mathrm{dBm}$. The 4 -stack 
RF-DC converter demonstrated an efficiency of $73.1 \%$ and an output DC voltage of $34.2 \mathrm{~V}$ at an RL of $4 \mathrm{k} \Omega$, and an input power per each stack of $21 \mathrm{dBm}$. The 4-stack has almost the same efficiency and four times higher output voltage compared to the single-stack. Figure 14 shows the simulated and measured efficiencies (in a) and output DC voltages (in b) of the implemented 4-stack RF-DC converter according to the various load resistances $(2,4,6,8$, and $10 \mathrm{k} \Omega)$. Since the rectifier was designed to have an optimum load of $4 \mathrm{k} \Omega$, it exhibited somewhat degraded efficiencies with other load resistances. However, as the load increases, the output DC voltage increases. Table 1 shows the performance comparison to the previously reported RF-DC converters using Schottky diodes at the frequency range (5-6) GHz. Compared to the previous works, the proposed 4-stack RF-DC converter exhibited very high output DC voltage and high efficiency.

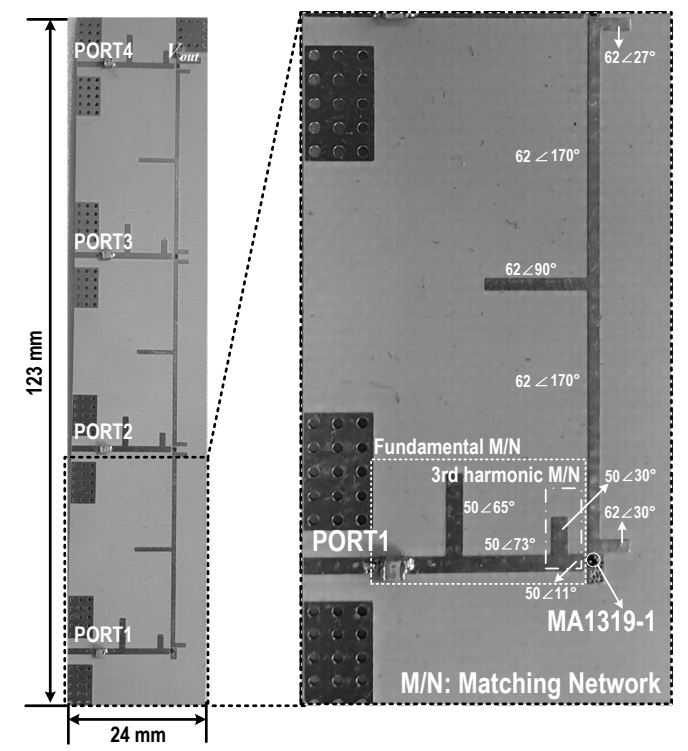

Figure 11. A photograph of the implemented 4-stack RF-DC converter.

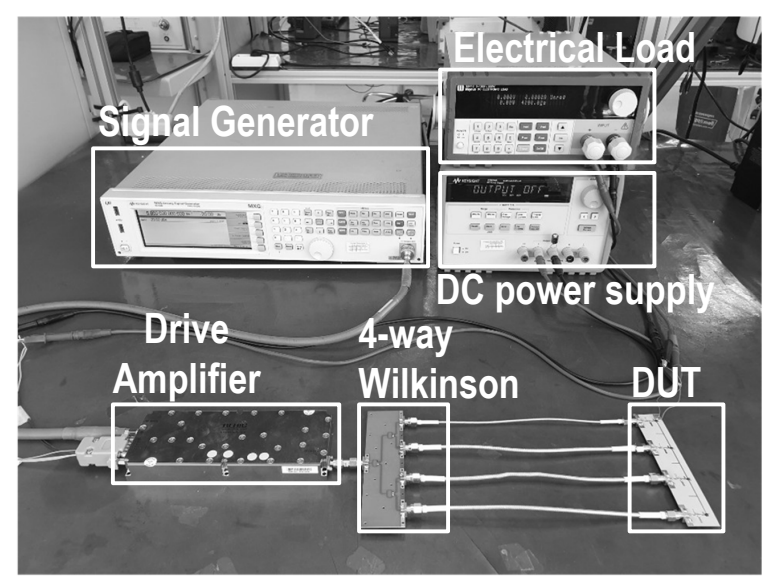

Figure 12. A photograph of the measurement setup. 


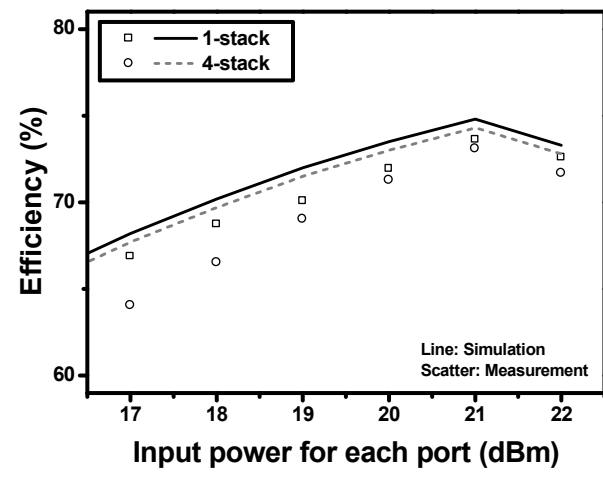

(a)

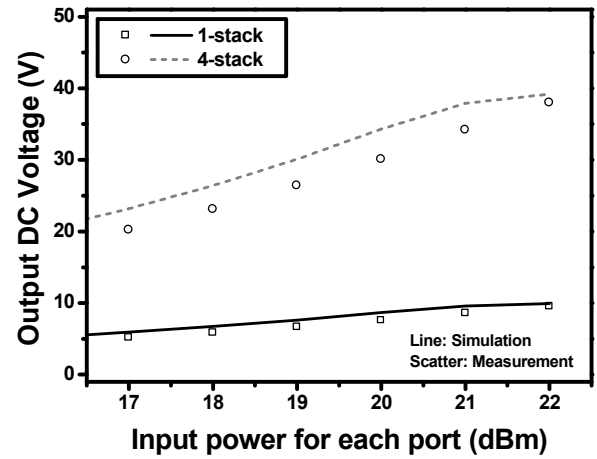

(b)

Figure 13. Simulated and measured results of the implemented single-stack and 4-stack RF-DC converters, (a) efficiencies and (b) output DC voltages.

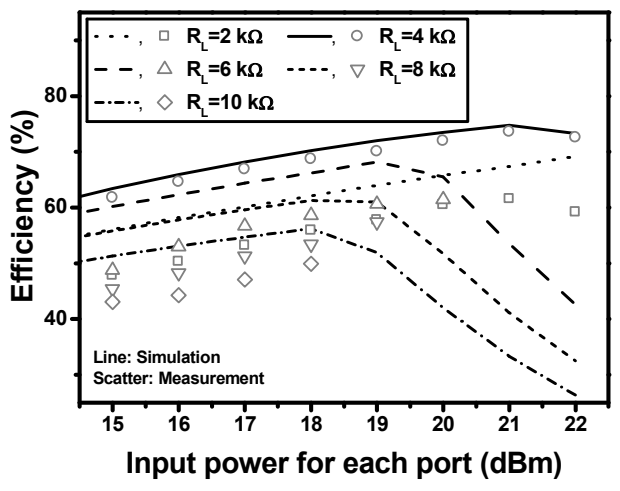

(a)

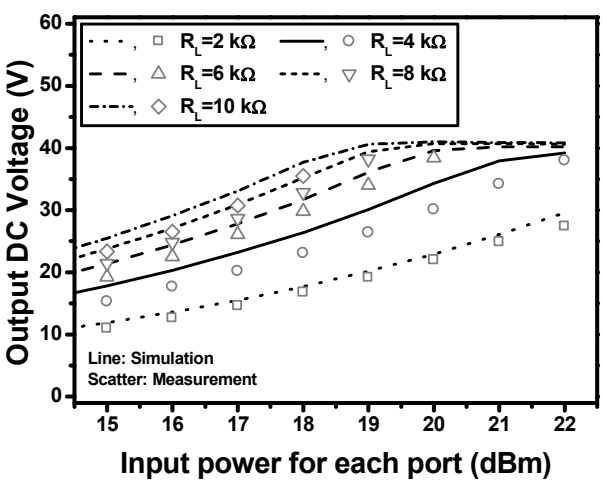

(b)

Figure 14. Simulated and measured results of the implemented 4-stack RF-DC converter according to the various load resistances, (a) efficiencies and (b) output DC voltages.

Table 1. Performance comparison to the previous works.

\begin{tabular}{|c|c|c|c|c|c|c|c|c|c|}
\hline Ref. & $\begin{array}{l}\text { Freq. } \\
\text { (GHz) }\end{array}$ & $\begin{array}{l}\text { Circuit } \\
\text { Topology }\end{array}$ & $\begin{array}{l}\text { Device } \\
\text { Type }\end{array}$ & $P_{\text {IN }}(\mathrm{dBm})$ & $\mathbf{R}_{\mathbf{L}}(\Omega)$ & $\begin{array}{c}\text { Output } \\
\text { Voltage } \\
\text { (V) }\end{array}$ & $\begin{array}{l}\text { Peak } \\
\text { Eff. } \\
(\%)\end{array}$ & $\begin{array}{l}\text { PCB } \\
\text { Size } \\
\left(\lambda_{0}^{2}\right)\end{array}$ & Technique \\
\hline [11] & 5.8 & Shunt diode & MA4E1317 & 17.65 & $\mathrm{~N} / \mathrm{A}$ & $\mathrm{N} / \mathrm{A}$ & 79.5 & $\mathrm{~N} / \mathrm{A}$ & $\begin{array}{l}\text { Harmonic control } \\
(\text { Class-F })\end{array}$ \\
\hline [12] & 5.8 & Voltage doubler & HSMS2860 & 14.77 & 1300 & $5.2 *$ & 71.0 & $\mathrm{~N} / \mathrm{A}$ & $\begin{array}{c}\text { Harmonic control } \\
(\text { Class-F })\end{array}$ \\
\hline [14] & 5.8 & Shunt diode & HSMS286B & 9 & 1300 & $\mathrm{~N} / \mathrm{A}$ & 60.6 & $1.12 \times 0.48^{*}$ & $\begin{array}{l}\text { Optimizaion of } \\
\text { output ripple }\end{array}$ \\
\hline [15] & 5.2 & Voltage doubler & HSMS286C & 24 & 1150 & 5.1 & 64.1 & $0.42 \times 0.33$ & $\begin{array}{c}\text { Harmonic control } \\
(\text { Class-F })\end{array}$ \\
\hline
\end{tabular}

* graphically estimated; $\lambda_{0}$ : wavelength at center frequency.

\section{Conclusions}

In this paper, a $5.8 \mathrm{GHz}$ RF-DC converter with a common-ground and multiple-stack structure using the RFIN was presented for high efficiency and high output DC voltage. The proposed RFIN was designed to isolate the RF signal, and to feed the DC voltage from one stack to the next stack, 
so that the DC voltage of each stack is combined at the output. The RFIN is composed of open-stubs, series transmission lines, and bond wires to have short-circuited fundamental and second harmonics for both ports. Since the RFIN is based on micro-strip transmission lines, the multi-stack RF-DC converter can be implemented on a PCB with a single dielectric layer for its bottom plate as a common ground for both RF and DC.

A $5.8 \mathrm{GHz}$ class-F voltage doubler was designed using bare-chip Schottky diodes for a unit stack of the RF-DC converter to obtain high efficiency. It has an optimum termination circuit for the third harmonics as well as the fundamental matching network at the input. Based on the class-F voltage doubler and RFIN, a single-stack and 4-stack RF-DC converters were implemented for comparison and verification.

The implemented 4-stack RF-DC converter was evaluated by exciting a CW signal with a frequency of $5.8 \mathrm{GHz}$. With an input power of $21 \mathrm{dBm}$ for each input port, an efficiency of $73.1 \%$ and an output DC voltage of as high as $34.2 \mathrm{~V}$ were achieved at an RL of $4 \mathrm{k} \Omega$, while the implemented single-stack RF-DC converter exhibited almost similar efficiency and four times lower output voltage. The proposed multiple-stack RF-DC converter can be applied to the Rx's of the MPT systems with massive antenna array. It can be used even in conjunction with other power-combining methods, such as RF power-combining, current-combining, or conventional voltage-combining methods for optimum system design.

Author Contributions: Conceptualization, J.B. and Y.Y.; Methodology, S.-H.Y.; Software, J.B. and W.C.; Validation, W.C. and H.K.; Formal Analysis, K.C.H. and K.-Y.L.; Investigation, J.B. and S.-H.Y.; Resources, J.B.; Data Curation, J.B. and Y.Y.; Writing-Original Draft Preparation, J.B.; Writing-Review and Editing, J.B. and Y.Y.; Visualization, Y.Y.; Supervision, Y.Y.; Project Administration, Y.Y.; Funding Acquisition, Y.Y.

Funding: This research was supported by the Korea Electrotechnology Research Institute (KERI) Primary research program through the National Research Council of Science and Technology (NST) funded by the Ministry of Science and ICT (MSIT) (No. 19-12-N0101-08).

Conflicts of Interest: The authors declare no conflict of interest.

\section{References}

1. Strassner, B.; Chang, K. Microwave Power Transmission: Historical Milestones and System Components. Proc. IEEE 2013, 101, 1379-1396. [CrossRef]

2. Shinohara, N. Power Without Wires. IEEE Microw. Mag. 2011, 12, 564-573. [CrossRef]

3. La Rosa, R.; Livreri, P.; Trigona, C.; Di Donato, L.; Sorbello, G. Strategies and Techniques for Powering Wireless Sensor Nodes through Energy Harvesting and Wireless Power Transfer. Sesnsors 2019, 19, 2660. [CrossRef] [PubMed]

4. Pinuela, M. Ambient RF energy Harvesting in Urban and Semi-Urban Environment. IEEE Trans. Microw. Theory Tech. 2013, 61, 2715-2726. [CrossRef]

5. Valenta, C.R.; Durgin, G.D. Harvesting Wireless Power: Survey of Energy-Harvester Conversion Efficiency in Far-Field, Wireless Power Transfer Systems. IEEE Microw. Mag. 2014, 15, 108-120.

6. Pizzotti, M.; Perilli, L.; del Prete, M.; Fabbri, D.; Canegallo, R.; Dini, M.; Masotti, D.; Costanzo, A.; Franchi Scarselli, E.; Romani, A. A Long-Distance RF-Powered Sensor Node with Adaptive Power Management for IoT Applications. Sensors 2017, 17, 1732. [CrossRef] [PubMed]

7. Nimo, A.; Grgić, D.; Reindl, L.M. Optimization of Passive Low Power Wireless Electromagnetic Energy Harvesters. Sensors 2012, 12, 13636-13663. [CrossRef] [PubMed]

8. Lu, X.; Wang, P.; Niyato, D.; Kim, D.I.; Han, Z. Wireless Networks with RF Energy Harvesting: A Contemporary Survey. IEEE Commun. Surv. Tutor. 2015, 17, 757-789. [CrossRef]

9. Roberg, M.; Reveyrand, T.; Ramos, I.; Falkenstein, E.A.; Popović, Z. High-Efficiency Harmonically Terminated Diode and Transistor Rectifiers. IEEE Trans. Microw. Theory Tech. 2012, 60, 4043-4052. [CrossRef]

10. Noda, A.; Shinoda, H. Compact Class-F RF-DC Converter with Antisymmetric Dual-Diode Configuration. In Proceedings of the 2012 IEEE MTT-S International Microwave Symposium Digest, Montreal, QC, Canada, 17-22 June 2012. 
11. Guo, J.; Zhang, H.; Zhu, X. Theoretical Analysis of RF-DC Conversion Efficiency for Class-F Rectifiers. IEEE Trans. Microw. Theory Tech. 2014, 62, 977-985. [CrossRef]

12. Wang, C.; Shinohara, N.; Mitani, T. Study on 5.8-GHz Single-Stage Charge Pump Rectifier for Internal Wireless System of Satellite. IEEE Microw. Mag. 2017, 65, 1058-1065.

13. Wang, D.; Negra, R. Design of a dual-band rectifier for wireless power transmission. In Proceedings of the 2013 IEEE Wireless Power Transfer (WPT), Perugia, Italy, 15-16 May 2013; pp. 127-130.

14. Lee, H.; Lee, J.-C. Optimization of a 5.8-GHz rectifier considering ripple amplitude and dc-voltage pattern. In Proceedings of the 2014 IEEE Wireless Power Transfer Conference, Jeju, Korea, 8-9 May 2014; pp. 212-215.

15. Bae, J.; Koo, H.; Lee, H.; Lim, W.; Lee, W.; Kang, H.; Hwang, K.C.; Lee, K.-Y.; Yang, Y. High-efficiency rectrifier(5.2 GHz) using a Class-F Dickson charge pump. Microw. Opt. Tech. Lett. 2017, 54, 3018-3023. [CrossRef]

16. Mansour, M.; Le Polozec, X.; Kanaya, H. Enhanced Broadband RF Differential Rectifier Integrated with Archimedean Spiral Antenna for Wireless Energy Harvesting Applications. Sensors 2019, 19, 655. [CrossRef] [PubMed]

17. Gasulla, M.; Ripoll-Vercellone, E; Reverter, F. A compact Thévenin Model for a Rectenna and Its Application to an RF Harvester with MPPT. Sensors 2019, 19, 1641. [CrossRef] [PubMed]

18. Ren, Y.-J.; Chang, K. 5.8-GHz Circularly Polirized Dual-Diode Rectenna and Rectenna Array for Microwave Power Transmission. IEEE Trans. Microw. Theory Tech. 2006, 54, 1495-1502.

19. Nishida, K.; Taniguchi, Y.; Kawakami, K.; Homma, Y.; Mizutani, H.; Miyazaki, M.; Ikematsu, H.; Shinohara, N. 5.8 GHz High Sensitivity Rectenna Array. In Proceedings of the 2012 IEEE MTT-S International Microwave Workshop Series on Innovative Wireless Power Transmission: Technologies, System, and Applications, Uji, Kyoto, Japan, 12-13 May 2011; pp.19-22.

20. Sakamoto, T.; Ushijima, Y.; Nishiyama, E.; Aikawa, M.; Toyoda, I. 5.8-GHz Series/Parallel Connected Rectenna Array Using Expandable Differential Rectenna Units. IEEE Trans. Antennas Propag. 2013, 61, 4872-4875. [CrossRef]

21. Yang, Y.; Li, L.; Liu, Y.; Zhang, B.; Zhu, H.; Huang, K. A Circularly Polarized Rectenna Array Based on Substrate Integrated Waveguide Structure With Harmonic Suppression. IEEE Antennas Wirel. Propag. Lett. 2018, 17, 684-688. [CrossRef]

22. Matsunaga, T.; Nishiyama, E.; Toyoda, I. 5.8-GHz Stacked Differential Rectenna Suitable for Large-scale Rectenna Arrays With DC Connection. IEEE Trans. Antennas Propag. 2015, 63, 5944-5949. [CrossRef]

23. Liu, Y.; Huang, K.; Zhang, B. A Low-Profile Lightweight circularly Polarized Rectenna Array Based on Coplanar Waveguide. IEEE Antennas Wirel. Propag. Lett. 2018, 17, 1659-1663. [CrossRef]

24. Almoneef, T.-S.; Erkmen, F.; Alotaibi, M.-A.; Ramihi, O.-M. A new Apporach to Microwave Rectenna Using Tightly coupled Antennas. IEEE Trans. Antennas Propag. 2018, 66, 1714-1724. [CrossRef]

25. Erkmen, F.; Almoneef, T.-S.; Ramihi, O.-M. A new Apporach to Microwave Rectenna Using Tightly coupled Antennas. IEEE Trans. Microw. Theory Tech. 2018, 66, 2433-2441. [CrossRef]

26. Lee, D.-J.; Lee, S.-J.; Hwang, I.-J.; Lee, W.-S.; Yu, J.-W. Hybrid Power Combining Rectenna Array for Wide Incident Angle Coverage in RF Energy Transfer. IEEE Trans. Microw. Theory Tech. 2017, 65, 3409-3417. [CrossRef]

(C) 2019 by the authors. Licensee MDPI, Basel, Switzerland. This article is an open access article distributed under the terms and conditions of the Creative Commons Attribution (CC BY) license (http://creativecommons.org/licenses/by/4.0/). 